\title{
Male-centered Mentality in Cao Zhi's Poems on Female Resentment
}

\author{
Shuguang Li \\ School of Literature \\ Jinan University \\ Guangdong, China 510632
}

\begin{abstract}
With distinctive male-centered mentality, Cao Zhi's poems on female resentment express the confirmation and maintenance of the central position of male dominance and indifference and negation to female value and life experience. The male-centered mentality is mainly reflected in the following aspects: firstly, the beauty of females is taken as the object of male appreciation and desire; secondly, female virtue is in fact the morality imposed on female according to the demand of male in male-dominated society; thirdly, the love to female and the responsibility to family of male are absent; fourthly, the construction of female social gender is completed through imagination and fiction. The male-centered mentality and the humble status of female are in close relation to the social class of Cao Zhi and the supreme authority of the monarchical power.
\end{abstract}

Keywords-Cao Zhi; poems on female resentment; malecentered mentality; social gender

\section{INTRODUCTION}

The authors of most poems on female resentment in classical Chinese poetry, apart from folk songs, are male. Although these works express the care and compassion to females, they are no doubt of distinctive male-centered mentality. To be specific, they express the confirmation and maintenance of the central position of male dominance and indifference and negation to female value and life experience. However, most researchers merely pay attention to the care and compassion to females but neglect the male-centered mentality. It seems that such a vague mentality is folded with a film of veil, so it is very interesting and meaningful to unravel the veil of language.

Cao Zhi's (192 - 232) poems on female resentment are typical examples. Playing an important role in the history of Chinese poetry, Cao Zhi is a famous poet of the state of Cao Wei of the Three Kingdoms period. In Review of Poetry by Zhong Rong, a literary critic of Southern Dynasties, the poems of Cao Zhi are rated as top grade. It is written that "Chen Si (Cao Zhi) is to poems what the Duke of Zhou and Confucius is to feudal order of importance or seniority in human relationships, dragon and phoenix to the birds, zither and reed pipe to music, and the pattern on the cloth of the emperor in embroidery". ${ }^{[1]}$ The "Confucius for poetry" lived in the era characterized by "awakening of human" and consciousness of literature". Human was emancipated from political indoctrination and ethical constraints to discover the individual life and value. The "awakening of human" promoted the "consciousness of literature". As a result, literature was independent from cultural and academic activities to demonstrate the wide range of diversified spiritual world. In this context, Cao Zhi's poems on female resentment present detailed and vivid emotion of females, yet the females were of a certain categories and modes absent of self-identity and spirit of independence. Therefore, they reflect the ideology imposed on females by maledominated society.

\section{BEAUTY: THE OBJECT FOR MALE TO APPRECIATE}

Females in the works of Cao Zhi are mostly beautiful, which is demonstrated in the most vivid and detailed way in The Beauty. The poem uses 16 sentences to portray the beauty of females. This is no accident. It is in close relation to the gender perspective of the narrator. The poem is written in the third person. The narrator is right the author, so it adopts the male perspective. Then, it is not surprising that there is much description on the beauty of female for a male author. In the poem, the beauty of female becomes the object of male appreciation and desire. Although appetite and sexual desire is human nature, the appreciation of beauty for male and female was extremely unfair in feudal society. On some occasions, male can appreciate female willfully, yet female can never appreciate male. In this sense, the work reflects a strong male-centered mentality.

In classical Chinese poetry, the relation between male and female is often compared to that between the emperor and officials. The poem expresses the grief of a female craving for marriage. Perhaps, it indicates the author's political aspiration. According to Wang Yaoqu of the Qing Dynasty, "Cao Zhi compares him with the female whose beauty is not appreciated for his unrecognized talents". ${ }^{[2]}$ After his brother Cao Pi ascended the throne, Cao Zhi suffered from repeated suspicion and repression. Suffering from an unsuccessful official career, Cao Zhi needed spiritual comfort than usual. Many frustrated literati chose to gain psychological compensation from wine or beauty. Cao Zhi is no exception. The beauty in his works added bright colors to his dull life and became a tool for him to find comfort. 
The Beauty is influenced by Mulberries on the Path, the Yufu Poetry of the Han Dynasty. After comparing the two, the male-centered mentality for appreciation hidden behind the work is further confirmed. Mulberries on the Path is a folk song created collectively, so it is difficult to determine its gender perspective in narration. Nevertheless, it seems that it adopts female perspective from the text. There will be a lot of discovery if we look at the two poems from the gender perspective. First of all, there is no direct description of the beauty of Luo Fu in Mulberries on the Path. The peerless beauty of Luo Fu is presented indirectly through the beauty of the environment, tools and clothes of Luo Fu when she was picking mulberry leaves and the reaction of others. There are in total 14 sentences in the work and 8 of them show the reaction of others. The Beauty combines direct portrayal and indirect presentation. 4 sentences show direct description and merely 2 sentences demonstrate the reaction of others. Secondly, although there is praise of male in Mulberries on the Path, the readers are mostly impressed by the sarcasm to male. However, the sarcasm to male becomes less important in The Beauty. The author attributes the reason for the difficulty in marriage of the beauty to her admiration for someone of high morality and her strict standards for marriage.

What are the reasons for the differences? The Beauty takes the male perspective to look at female from the eyes of male, so it pays much attention to the appearance and increases description of the appearance of the female to take her as the object of their desire and appreciation. As for the attitude to male, it should be denial for the logic of writing, yet the author just gives a hint because of his self-esteem as a male. Male can observe female, and vice versa. In Mulberries on the Path, we can find the narrator observe male to demonstrate the sarcasm to male observers and the official as well as the appreciation to the husband of Luo Fu. It is also found that female would spare no efforts to mock male.

\section{VIRTUE: THE REFLECTION OF MALE'S WILL}

The females in the works of Cao Zhi have not only beauty but also good virtue. A diversity of restrictions on female in male-centered feudal society is reflected on them. Those who can comply with the ethical principles are considered as of "female virtue" and set as examples of others. The female images in the works of Cao Zhi are of such "female virtue", which is particularly striking in The Abandoned Wife.

Let's take a look at the reason for the abandon of the woman. In the Jian'an era at the end of the Han Dynasty, a military officer called Liu Xun under Cao Cao's command abandoned his wife Wang Song. The event evoked strong repercussions in the literati at Ye Xia. Cao Zhi wrote the poem The Abandoned Wife on the basis of it. Starting with the flourishing pomegranate trees without fruits, he revealed that the woman was abandoned for "childless". In On Duckweed, it is written that "dogwood does have its fragrance, but can't be compared with laurel or orchid. Your new wife may be beautiful, but still she's not as pleasing as the old". It indicates that the reason for a male to be fickle in his affections is that the female gets old. When a woman is abandoned, it is because either that she is childless or that she is getting old. Childless was one of the seven reasons for abandoning a wife in ancient society in China. Nevertheless, "seven reasons for abandoning a wife" had not been strictly implemented before the Tang Dynasty. Besides, man could keep concubines to have children, so it was rare for a man to abandon his wife for childless in ancient time, which was the reason for the event to evoke strong repercussions. It can be concluded that there were some other reasons for Liu Xun to abandon his wife and childless was merely an excuse. According to New Songs from the Jade Terrace, "Wang Song is the wife of General Liu Xun of Ping Lu. After they were married for over twenty years, Liu Xun turned to the daughter of Sima in Shan Yang and abandoned Wang Song at the excuse of childless". ${ }^{[3]}$ It pointed out the truth directly. Abandon one's wife for her getting old was not in the seven reasons for abandoning a wife. It is the result of abuse of the right of male. In poems of Cao Zhi, females were abandoned in unjustified ways.

Then what is the mentality of them after being abandoned? In The Abandoned Wife, she cannot sleep at night and played the lute, so she lacked the spirit of resistance. Judging from the sentence that "If you're childless, you should go home", it seemed that the woman had accepted the reason for his abandon. Moreover, she even fancied that she could give birth to a son and gain the favor of his husband again. How naive and infatuated she was. In Planting Arrowroot, the abandoned woman lingered about in the northern forest with bad mood and finally sighed to resign herself to the fate. In Duckweed, the abandoned woman looked at the sky and sighed deeply. Her tears dropped one after another in the hope that the broken mirror could be joined together. In short, the abandoned women in Cao Zhi's poems could only sigh and shed tears. Without the spirit of resistance and hoping for recovering the favor of their former husband, they seem so naive.

"Abandoned for no reason---sigh and shed tears---hoping for reunion" represents the pattern for Cao Zhi to construct the image of female in these poems. Males have the absolute power to deal with them. Although they suffer from the oppression of males, they could hardly awaken. They conscientiously abide by the ethical principles of the feudal society, so they lack independent personality and rebellious spirit and show a strong sense of reliance on males. It can be concluded that females often build themselves according to the demand of males.

\section{WAITING: DISAPPEARANCE OF MALE MORALITY}

Several poems about female waiting for her husband in Cao Zhi's poems of female resentment are thoughtprovoking. The basic pattern for these works is as follows: the husband had left home for years without any trace, yet the wife waited for him at home with never changing affection. At the beginning, it seems that these poems are of no difference from works of others. However, after careful observation, it is discovered that male morality disappears in Cao Zhi's works. In other words, no trace of the affection of 
the husband to his wife and his responsibility to the family could be found.

Let's take A Groan as an example for analysis. In the poem, the husband had left home for over a decade and there was not any message from him, so the wife was to some extent worried about the love between them. "Her man is like dust on the way, she is like the trodden-down clay. They go up or down like a tide, when can they together abide?" In the four lines, "dust on the way" and "trodden-down clay" in different situation are used to show the two sides, which demonstrate the worry of the wife that her husband would abandon her.

Someone would argue that in the warring period of Wei and Jin Dynasties, the turbulent situation resulted in the separation of husband from the wife without any message. It makes sense, yet it is not completely convincing. The Nineteen Old Poems were created earlier than the poems of Cao Zhi. Though the social background is basically similar, the situation of the women waiting for their husbands is different. For example, Parted Lovers not only describes the yearning of the wife for her husband but also the yearning of the husband for his wife. "But the stream brims always between. And, gazing at each other, they cannot speak" demonstrates their loyalty to love. A Guest from Afar and Chilly Winter describe the stories of the husband sending gift or letter from afar to his wife to express his yearning for her. In Northwest Tower, the male abandons the undervaluing of women by feudal orthodoxy to take the female as a bosom friend, which is of valuable humanistic sentiment.

After comparing the above-mentioned poems with Cao Zhi's works, the male-centered mentality can be clearly found in the latter. In modern society, love should be established on the basis of equality between the two sides. As an intellectual of the feudal society, Cao Zhi could by no means have such understanding. However, his understanding of love is even more superficial than that of the author of Nineteen Old Poems. In Cao Zhi's works, when males leave home for years for whatever purposes, they show no care and yearning for their wives, which reflects the relentlessness of male to female in male-centered society.

\section{IMAGINATION: CONSTRUCTION OF FEMALE GENDER}

Females in Cao Zhi's works are both beautiful and virtuous. They reflect almost all requirements of the feudal society for females. However, the image is not fully consistent with the historical facts. Based on common sense, females would inevitably have resentment after being abandoned or alienated by their husband, yet those in Cao Zhi's poems express no dissatisfaction or complaints apart from sighing, shedding tears, and expressing grievance. This is clearly the author's will and imagination, which could be proven by the portrayal and description of female in history books and other poems.

Females in history books are mostly imperial concubines competing for the favor of the emperor frequently. Take Biographies of Empresses and Concubines.Book of Wei-Records of the Three Kingdoms for example, two of the five concubines in the book commit suicide by the imperial order for fighting for his favor. With regard to the Book of Songs, the reason for abandon of females in it is basically the same to that in Cao Zhi's works, yet the reaction of females to the abandon is obviously different in two aspects: one is that the abandoned females in Cao Zhi's works expresses no complaint and condemnation despite of sorrow and sadness, while those in the Book of Songs directly show criticism and resentment to their husbands. A Simple Fellow is an example, "I did no wrong, you were the one to blame; It was you who were faithless and changed". Secondly, the abandoned females in Cao Zhi's works are reluctant to part from their husbands and some of them even hope that their husbands can change their mind, yet those in the Book of Songs all have sober understanding of their fate. For example, it is written in Valley Wind that "I am not accepted by my husband and how can I consider what would happen after leaving".

For the females in Cao Zhi's works, history books, and Book of Songs, which are closer to the historical fact? The answer is clear. The females in Cao Zhi's works are to a certain degree fictitious and imaginary. All literature works would use fiction and imagination according to the aesthetic ideal of the author. The purpose of Cao Zhi is to enhance the social gender of these female.

Social gender is a concept created by western feminist scholars. In accordance with their theory, gender can be divided into two categories: biological sex and social gender. Biological sex is the natural different between male and female in physiological feature. Social gender, also called cultural gender, is the gender feature and difference of male and female under the social culture structure based on their biological sex in the form of fixed expectation of the society for the role of male and female in economy, politics, and society.

The biological sex and social gender is usually the same, yet sometimes they could also be different. When females act according to the demand of the feudal society and follow "the three obediences and the four virtues", or when they maintain the consistency between their social gender and biological sex, they could be recognized by the mainstream value. Once the two are inconsistent, the females would suffer from criticism and disputes. For example, the heroine in A Simple Fellow -Odes of Wei. Book of Songs, married her husband freely without gaining the consent of their parents or following the procedure of matchmaking and later was abandoned. Because the behavior is was not in line with the feudal ethics, it was criticized frequently in ancient times. In Preface to Mao Poetry, it is written that "A Simple Fellow satirized the society at that time. Under the rule of Duke Xuan, there was no social ethics and people were dissolute. Male and female seduced each other. " ${ }^{[4]}$ In Collection of Book of Songs by Zhu Xi, "the immoral woman was abandoned. She told her story to express her remorse". ${ }^{[5]}$

Social gender is developed in the society under the comprehensive influence of social economy, politics, and culture. In The Second Sex, the French writer Simone de Beauvoir wrote, "women are not born females but gradually developed. Physically, psychologically, or economically, no 
fate can determine the image of females in society. It is the civilization as a whole that determines the so-called female temperament between male and eunuch. Only through the intervention of another can one be established. A child, in terms of existence, can hardly realize its gender". ${ }^{[6]}$ Here, Simone de Beauvoir stressed the role of "the civilization as a whole" in shaping female. During the process, language, as the carrier of culture and tool of thinking, plays an important role in construction of social gender. As some commentators have pointed out, "gender is a dynamic term. It is consistently constructed in different practical activities, while language is an important way for construction of gender". ${ }^{[7]}$ It is through his language of poem and some imagination and fiction that Cao Zhi imposed feudal ethics and morality on females to complete the construction of female social gender.

\section{CONCLUSION}

In conclusinon, Cao Zhi's poems on female resentment show distinctive male-centered mentality. It has the following three major reasons.

First of all, females were at very humble social status in feudal society. For their distinctive physical structure, females gradually retreated to family in social division of labor and became dependent on males economically. This gradually promoted the culture tradition that "females are inferior to males". For example, it is written in Guliang Zhuan that "(a woman) should be obedient to her father at home, to her husband after marriage, to her eldest son after the death of her husband. Woman should never be independent". ${ }^{[8]}$ The idea had been promoted by feudal orthodox in later dynasties.

Secondly, the social status of Cao Zhi is different from general public and ordinary literati. The reason for Cao Zhi's poems to pay more attention to male-centered mentality than Books of Songs, Mulberries on the Path, and Nineteen Old Poems is that the authors of the latter are either general public or ordinary literati who are of different social class from Cao Zhi of the royal family. The family background and education of Cao Zhi determines that he can receive more feudal orthodox ideas. The indifference and denial of female emotion and value is the inevitable imprint of his social class.

Thirdly, Cao Zhi's poems also have the textual potential to compare females with unrecognized talents. According to the traditional theory of "Yin Yang", the relationship between male and female is often used to express the relationship between the emperor and his subordinates. Male and emperor belong to Yang and take the dominant role and female and subordinates belong to Yin and take the subordinate role. Cao Zhi's poems on female resentment mostly expressed his political aspiration. ${ }^{[9]}$ They indicate the complaints of the author for committing crime for no reason after the year of Huangchu and his wish that his talents can be recognized. In this way, they cover two layers of meaning. Internally, they describe the relationship between male and female. Externally, they indicate the relationship between the emperor and his subordinates. Such a potential of the text makes the male-centered mentality in Cao Zhi's poem the symbol of the authority of the emperor. As a result, the females in his works are all gentle and honest. Even though they have unlimited resentment, they never take male as their target of criticism and males have never give mercy to females.

\section{REFERENCES}

[1] (Liang) Zhong Rong, Translated by Zhou Zhenfu, Review of Poetry, Beijing: Zhonghua Book Company, 1998, pp.37.

[2] Teaching and Research Group on Classical Literature, Chinese Department, Hebei Normal University, Compilation of Documents on Cao Cao, Cao Zhi, and Cao Pi, Beijing: Zhonghua Book Company, 1980, pp.176.

[3] (Chen of Southern Dynasties) Xu Ling, Noted by (Qing Dynasty) Wu Zhaoyi, Proofread by Shang Cheng, New Songs from the Jade Terrace, Shanghai: Shanghai Guji Press, 2013, pp.60.

[4] Preface to Mao Poetry: Volume 69, The Four Categories of Pavilion of Literary Profundity, Shanghai: Shanghai Guji Press, 2003, pp.15.

[5] (Song Dynasty) Zhu Xi. Collection of Book of Songs: Volume 72, The Four Categories of Pavilion of Literary Profundity, Shanghai: Shanghai Guji Press, 2003, pp.772.

[6] (France) Simone de Beauvoir. Translated by Tao Tiezhu. The Second Sex, Beijing: Chinese Books Publishing House, 1998, pp.309.

[7] Shi Dongqin, Overview of Difference between Language and Gender, Foreign Language Research. 2007(5), pp.40.

[8] (Qin Dynasty) Zhong Wenzheng, Thirteen Classics Exegesis·Note for Guliang Zhuan, Beijing:Zhonghua Book Company, 1996, pp.51.

[9] Feng Rulou.On Cao Zhi's Poem on Female , Suzhou University Journal (Philosophy and Social Science), 1996(4), pp.76-80. 